\title{
Percepção de crianças hospitalizadas sobre realização de exames"
}

\author{
HOSPITALIZED CHILDREN'PERCEPTION ON EXAM ACCOMPLISHMENT \\ PERCEPCIÓN DE NIÑOS HOSPITALIZADOS SOBRE REALIZACIÓN DE EXAMENES
}

\author{
Virgínia Virgilio Soares ${ }^{1}$, Luiza Jane Eyre de Souza Vieira²
}

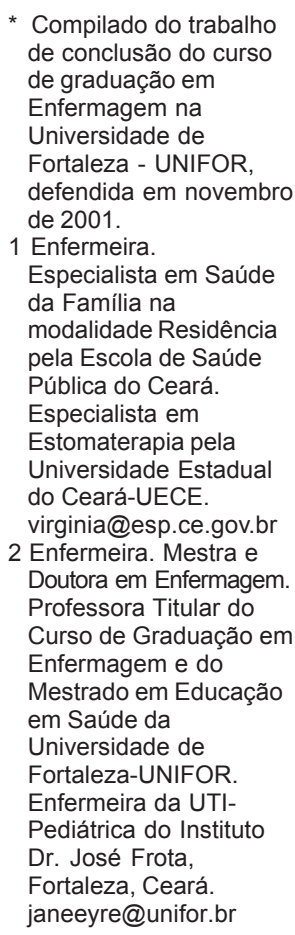

\author{
RESUMO \\ O estudo teve como objetivo \\ identificar a percepção da \\ criança hospitalizada, em \\ idade escolar, sobre a \\ realização de exames. Foi \\ utilizada a pesquisa de \\ natureza descritiva, \\ predominando a investigação \\ de caráter qualitativo. $O s$ \\ resultados revelaram que as \\ crianças cooperam com os \\ exames apesar do medo. $O$ \\ medo foi relacionado ao temor \\ da dor física, de ser \\ machucado, e ainda, do \\ desconhecido. Considera-se \\ que a criança percebe a \\ realização do exame como \\ parte do seu tratamento e \\ gostaria de receber \\ explicações sobreo \\ procedimento.
}

\section{PALAVRAS-CHAVE}

Criança hospitalizada. Exames médicos.

Terapêutica.

\author{
ABSTRACT \\ The study had as objective to \\ identify the hospitalized \\ children's perception, in \\ school age, about the \\ accomplishment of exams. \\ The research of descriptive \\ nature was used, prevailing \\ the investigation of qualitative \\ character. The results \\ revealed that the children \\ cooperate with exams despite \\ the fear. The fear was related \\ to the dread of the physical \\ pain, being hurt, or even the \\ unknown. It is considered that \\ the child notes the exam \\ accomplishment as part of his/ \\ her treatment and he/she \\ would like to receive \\ explanations about the \\ procedure.
}

\section{KEYWORDS}

Child hospitalized.

Medical examination.

Therapeutics.

\section{RESUMEN}

EI estudio tuvo como objetivo identificar la percepción del niño hospitalizado, en edad de ir a la escuela, sobre la realización de exámenes. Fue usada la investigación de naturaleza descriptiva, prevaleciendo la investigación de carácter cualitativo. Los resultados revelaron que los niños colaboran con los exámenes a pesar del miedo. EI miedo se relacionó con el temor al dolor físico, a ser herido, o aún, a lo desconocido. Se considera que el niño percibe la realización del examen como parte del tratamiento e desearía recibir explicaciones sobre el procedimiento.

\section{PALABRAS CLAVE}

Niño hospitalizado.

Exámenes médicos.

Terapéutica. 


\section{INTRODUÇÃO}

A assistência de forma integral voltada à criança se faz presente na grande maioria dos documentos oficiais que delineiam as políticas públicas de saúde. Nos ambulatórios ou em instituições hospitalares, o atendimento deve ser prestado com uma abordagem holística, lembrando e respeitando a condição do "ser criança". O cuidado dispensado à criança hospitalizada deve ultrapassar a prestação de cuidados físicos e os conhecimentos a respeito de sua doença e dos tratamentos clínicos que devem ser realizados. As necessidades emocionais e sociais da criança devem ser consideradas, além de abranger a utilização de técnicas adequadas de comunicação e relacionamento ${ }^{(1)}$.

Os profissionais responsáveis pela realização de exames laboratoriais e de imagenologia são agentes na execução de procedimentos na enfermaria pediátrica, imprimindo mudanças no processo de trabalho da enfermagem. Em geral, as tarefas hospitalares são permeadas de rotinas, às vezes extenuantes, o que acaba por dificultar a consagração de tempo ao cliente pediátrico.

A literatura indica que, quando uma criança é hospitalizada, as pessoas que irão cuidar de sua saúde poderão influenciar em seu desenvolvimento emocional, podendo essa influência ser tanto positiva quanto negativa $^{(2)}$. Perante o exposto, interrogamos: estarão os profissionais de saúde aptos a fornecer uma abordagem adequada a essas crianças durante o período de hospitalização? Acreditamos que a resposta a tal questionamento seja uma vertente a ser trilhada para a tão almejada hospitalização infantil, centrada nos princípios do respeito e da compreensão da tríade do agravo à saúde-criança-família.

A motivação para realizar este trabalho partiu da convicção de que, para toda e qualquer assistência à criança hospitalizada, torna-se necessário um conhecimento prévio da situação enfrentada e vivenciada por ela. Isso levará a reconhecer o seu comportamento, facilitando, sobremaneira, o estabelecimento da comunicação, o que influirá diretamente na excelência dos cuidados prestados.

Ao investigar sobre os sentimentos da criança hospitalizada frente à equipe de enfermagem, foi identificado o desconhecimento - por parte da criança — da própria patologia, do tratamento e dos exames realizados e a realizar ${ }^{(3)}$, contrariando o que preconiza o Estatuto da Criança e do Adolescente $^{(4)}$. Na mesma investigação, ficaram também evidenciados pela criança o medo, a ansiedade e a resistência aos procedimentos. Consoante a literatura,

o pensamento mágico e o simbolismo na criança dificultam as intervenções corporais, porque ambos permitem-na acreditar que suas idéias e pensamentos são reais, explicando suas respostas diante de situações difíceis ${ }^{(5)}$.

Refletindo sobre essas ponderações e partindo do princípio de que os exames complementares para auxílio diagnóstico e terapêuticos são procedimentos que exigem técnica e sensibilidade daqueles que os fazem, percebemos a necessidade de ampliar nosso conhecimento sobre a percepção da criança hospitalizada quanto à realização de exames laboratoriais e diagnósticos. Esperamos contribuir para que os profissionais de saúde tenham mais um subsídio para agir no preparo emocional da criança nas situações de angústia e estresse no contexto da hospitalização.

A hospitalização da criança significa agressão ao seu mundo lúdico e mágico e, por isso, requer do profissional que a assiste, a compreensão do mundo infantil. "Cuidar significa incluir a atenção e o respeito aos aspectos emocionais e psicológicos durante todo o processo terapêutico; nesse processo está inclusa a realização dos procedimentos técnicos ${ }^{(6)}$.

De todos os profissionais da saúde envolvidos na assistência, o enfermeiro é um dos que tem maior encargo nessa humanização. Isso em virtude de manter sob sua responsabilidade um grande número de profissionais de enfermagem, dentre os quais aqueles que tanto estão diretamente envolvidos com a realização de procedimentos laboratoriais, como também permanecem longos períodos com a criança hospitalizada. É necessário integrar ao exercício profissional e aos recursos tecnológicos a compreensão das etapas de crescimento e desenvolvimento da criança, para que seja mantido o atendimento humanístico a um ser que pensa e sente, e não a um aglomerado de sinais e sintomas. A presença humanizada de quem cuida poderá representar ao profissional de saúde
Percepção de crianças hospitalizadas sobre realização de exames 
a certeza de ter promovido, dentro de suas possibilidades, uma melhor qualidade de vida e de bem-estar àquele que estava temporariamente sob seus cuidados.

Certos exames são invasivos, agressivos e dolorosos, ou ainda requerem uma aparelhagem complexa que emite sons e ruídos, constituindo exigências técnicas de alguns tratamentos para auxílio diagnóstico e terapêutico. Esses procedimentos, embora não possam ser evitados, podem ser suavizados pela sensibilidade da assistência. Na visão dos autores ${ }^{(3,6)}$, a assistência humanizada não é só condição técnica, mas, prioritariamente, solidariedade, amor e respeito pelo ser humano, uma vez que a criança, em sua condição indefesa, busca nos adultos apoio, carinho e compreensão.

Nessa perspectiva, o estudo teve como objetivo identificar a percepção da criança hospitalizada, em idade escolar, sobre a realização dos exames durante o período de internação.

\section{TRAJETÓRIA METODOLÓGICA}

Trata-se de um estudo descritivo, com abordagem qualitativa, para compreender a subjetividade expressa no discurso das crianças sobre a percepção dos exames aos quais são submetidas. A literatura nos informa que a qualidade representa a intensidade das coisas ${ }^{(7)}$. Dessa forma, a pesquisa se baseou na premissa de que

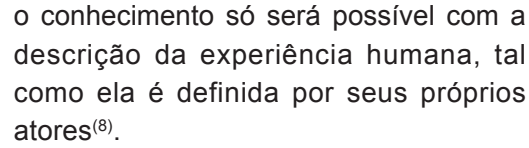

O estudo foi realizado em um hospital infantil de assistência terciária, que integra a rede pública estadual, localizado no Município de Fortaleza. A escolha dessa instituição decorreu do fato de ser referência estadual no atendimento de crianças e adolescentes em situações clínicas, cirúrgicas e oncológicas.

Participaram do estudo crianças com 6, 8, 10 e 12 anos, que se submeteram à realização de exames complementares ou de esclarecimento diagnóstico, tais como coleta de sangue, exame de líquor, raios $\mathrm{x}$ de tórax, tomografia computadorizada, endoscopia digestiva, ultra-sonografia abdominal, eletro- cardiograma, e que permaneceram hospitalizadas no período de setembro e outubro de 2001. Essas crianças eram portadoras de afecções respiratórias, doenças do sistema músculo-esquelético, leucemia e situações cirúrgicas.

Optamos por crianças na fase escolar, pois, nessa etapa, elas encontram-se em condições intelectuais de compreender melhor o seu corpo e sua doença. A concepção da doença vai ficando mais ampla, complexa e realista à medida que a criança amadurece. Sua reação varia de acordo com o seu nível de compreensão, decorrente da fase da vida em que se encontra ${ }^{(9)}$.

Adotamos a classificação escolar de acordo com Whaley e Wong ${ }^{(10)}$, a qual determina que esse período compreende a faixa etária entre 6 e 12 anos, contrariando a classificação da Organização Mundial de Saúde (OMS), que postula a fase escolar como o período entre 6 e 10 anos. A justificativa para a classificação adotada foi à inclusão de escolares com idade entre 10 e 12 anos, resultando no total de onze crianças/adolescentes participantes do estudo.

O princípio de autonomia foi respeitado, sendo solicitado o consentimento verbal e escrito da mãe ou responsável e principalmente o da criança/adolescente, após informações sobre a pesquisa. Quando são utilizados indivíduos como sujeitos de investigações científicas, como costuma ocorrer na pesquisa em enfermagem, precisa-se ter muito cuidado para assegurar a proteção dos direitos dessas pessoas ${ }^{(8)}$. Para tanto, a pesquisa trilhou os caminhos de acordo com a Resolução 196/96 do Conselho Nacional de Saúde, que preconiza as diretrizes nas pesquisas envolvendo seres humanos ${ }^{(11)}$.

A coleta de dados ocorreu nos já referidos meses de setembro e outubro de 2001, tendo como instrumentos à observação e a entrevista semi-estruturada, constando de questões norteadoras que versavam sobre hospitalizações anteriores, exames já realizados, o pior exame, o porquê da realização de exames durante a hospitalização, o conhecimento da criança quanto à profissão das pessoas que realizaram os exames, a importância da explicação anterior à realização dos exames, e o atendimento ideal durante a realização dos exames. 
Inicialmente, foi preciso dialogar com as crianças predisponentes ao estudo, na tentativa de estabelecer um clima de confiança. Passada essa fase, utilizou-se um gravador, porém a permissão para utilizar esse equipamento ficou a critério do sujeito da pesquisa. Ressaltamos aqui que o gravador foi utilizado em todas as entrevistas, constituindo-se, para a maioria, um atrativo à participação das crianças no estudo.

Analisar os dados de uma pesquisa consiste em se reportar às fases de sua construção buscando um encadeamento lógico e contextual. Para que o fato aconteça, é necessário que o pesquisador realize uma transposição reflexiva ao cenário físico e cultural. Corroborando nosso entendimento, a análise de conteúdo parte de uma literatura de primeiro plano para chegar a um nível mais profundo, ou seja, aquele que ultrapassa os significados manifestos. Assim sendo, articula os textos descritos e analisados com os fatores que determinam suas características: variáveis psicossociais, contexto cultural, social e o processo de produção de mensagem ${ }^{(12)}$.

Os dados foram analisados sob a óptica da análise avaliativa ou representacional, cuja finalidade consiste em medir as atitudes do sujeito sobre o que fala - pessoas, coisas, acontecimentos. Semelhante à análise temática, esta separa o texto em unidades de significação em termos de direção e de intensidade dos juízos selecionados. Desse modo, o material foi analisado em três momentos: leitura flutuante de todo os dados, exploração do material com a catalogação e codificação em unidades de significação e, por último, tratamento e interpretação dos resultados $^{(12)}$.

Para facilitar a operacionalização da análise, registramos em folhas de papel-madeira as questões norteadoras da entrevista, juntamente com as respostas de todos os participantes. Utilizamos a codificação através de cores, circulando as palavras ou frases-chave significativas à elucidação do objetivo do estudo. Através das convergências e similaridades das falas, emergiram as seguintes categorias: Finalidade dos exames realizados, Reações provocadas pelos exames, Profissional que realiza o exame e Atendimento esperado, as quais fundamentaram a percepção da criança hospitalizada sobre a realização dos exames. .

\section{CARACTERIZAÇÃO DO CONTEXTO DA CRIANÇA HOSPITALIZADA}

Diante do contexto de hospitalização das crianças do estudo, foram encontradas patologias diversas, abrangendo distúrbios respiratórios, músculo-esqueléticos, situações cirúrgicas, afecções neoplásicas como a leucemia, entre outras. Essa diversidade de situações de doença vivenciadas pelas crianças amplia os conceitos de hospitalização e todos os outros relacionados a ela, pois a reação da criança é diretamente dependente do que ela vivencia. As crianças responderam às mesmas perguntas de urna maneira diferente, enfocando de forma positiva ou negativa as suas experiências.

Encontramos uma criança ( 7 anos) com diagnóstico de leucemia, que entendia e descrevia a própria doença com total correção, repleta de detalhes terapêuticos e sem aparentar sofrimento. Entretanto, encontramos outra (10 anos), com o mesmo diagnóstico, que estava apática e concisa, referindo-se a uma palidez como motivo da hospitalização. Isto causou espanto na mãe.

A explicação para a atitude da primeira criança, de acordo com a literatura ${ }^{(13)}$, é a mobilização do que se chama defesa da linha obsessiva, valendo-se de intelectualizações, racionalizações e anestesia dos sentimentos. Essa é uma forma de lidar com a ansiedade típica dessa etapa vital. Já a postura adotada pela segunda criança pode decorrer dos efeitos depressivos da doença, levando ao mecanismo de defesa de negação. Com isso, a dificuldade de falar sobre a doença pode indicar a percepção de sua importância, pois, segundo a Psicanálise, reprimimos o que é importante ${ }^{(13)}$.

Diante desses episódios, podemos perceber que a reatividade da criança à doença e à hospitalização engloba um universo amplo de fatores, existindo um elo entre o psíquico e o físico. Identificamos que as reações gerais frente à hospitalização dependem de cinco fatores:

(1) estágio evolutivo da criança;

(2) grau de sofrimento e mutilação e significado que a doença tem para a criança e os pais;

(3) relação pai-filho e a resposta da criança à reação dos pais;

(4) relação psicológica da criança aos procedimentos médicos e cirúrgicos, separações e hospitalizações; e,
Percepção de crianças hospitalizadas sobre realização de exames 
Virgínia Virgilio Soares Luiza Jane E. de S. Vieira
(5) interferência resultante nas funções físicas, psicológicas e sociais ${ }^{(10,13)}$.

Caracterizando a percepção da criança sobre a realização de exames, discorremos sobre as categorias que emergiram no estudo.

\section{Finalidades dos Exames Realizados}

...Ih, eu já fiz um bocado!

As crianças estudadas, em geral, permitiram e até cooperaram na realização dos exames, apesar de não gostarem deles, em virtude do desconforto ou da dor. Algumas choraram ou choramingaram, dificultando, às vezes, a realização dos exames. Apesar de sentir dor ou medo na realização de alguns exames, a maioria compreendeu a sua necessidade. Tais falas ilustram essa compreensão:

A gente tem uma doença, ai o exame sabe. (P.H., masculino, 12 anos, exame de líquor).

Pra saber se a pessoa fica hospitalizada. Por exemplo, o raio-x é pra saber como está os ossos. (J.L., masculino, 8 anos, raios $\mathrm{x}$ de tórax e coxa).

Eu quero sair logo daqui, e primeiro têm que descobrir. Ninguém sabe o que eu tenho. (R., feminino, 6 anos, exame de sangue).

Como foi visto, os exames foram relacionados à elucidação diagnóstica e ao acompanhamento da terapêutica adotada. A menção dos estados de melhora ou piora foi referida também como objetivo dos exames realizados.

Porque serve pra saber se eu tô melhor.

(N., masculino, 7 anos, mielograma).

É pra saber se o problema voltou.

(N., feminino, 10 anos, mielograma).

Percebemos uma diferença nas respostas, dependendo da cronicidade ou do estado agudo da doença. Essas duas últimas crianças, portadoras de leucemia, relacionaram o exame à terapêutica como uma forma de acompanhamento. Enquanto isso, as outras fizeram referência ao diagnóstico e aos achados que poderiam elucidar o seu problema de saúde.

Os exames laboratoriais e de imagem estão cada vez mais sofisticados e seguros, auxiliando no conhecimento do diagnóstico de inúmeras patologias. No entanto, apesar de todo o avanço, a indicação do tipo de exame está relacionada com a patologia de base e suas possíveis complicações no tocante à realização do exame físico do paciente, fazendo com que os exames sejam sempre complementares, ou seja, um adicional do raciocínio clínico. Somente dessa forma, será possível avaliar a relação de custo-benefício que cada um dos métodos propiciará.

Os exames mais freqüentes no estudo foram os de sangue e os de raio $\mathrm{x}$. A explicação para isso concentra-se na variedade de exames de sangue, pelo fato de alguns serem de rotina diagnóstica e característicos de um acompanhamento terapêutico. Já os de raio x estão relacionados à doença de base ou complicações decorrentes da exposição ambiental aumentada, como infecções respiratórias, por exemplo.

O exame, para a criança, é compreendido como parte do seu tratamento, seja para revelar o diagnóstico, seja para acompanhar o curso da doença e, conseqüentemente, o doente, monitorando recidivas, involuções, como também estados de melhora. É um passo para se libertar da hospitalização, uma vez que, conhecendo a sua doença, ela poderá ter um tratamento direcionado e logo retornará para casa. Identificamos, então, que a criança reconhece a importância de se realizar um exame durante o período de internação a que fica submetida.

\section{Reações provocadas pelos Exames}

Dentre as reações apresentadas pelas crianças, em decorrência da realização dos exames, salientamos a dor e o medo.

Dor:

...Uma agulhada aí, doeu!

A dor foi um sintoma vivenciado pela totalidade das crianças, estando associada a várias situações e, principalmente, referendada nos exames. Os exames que originam sensações dolorosas, como os de sangue, dentre todos aqueles realizados com agulhas, foram os maiores desencadeadores de caretas e de falas que soavam ríspidas e não titubeantes, quando se perguntou sobre o pior exame. As verbalizações das crianças comprovam a percepção dolorosa:

Porque deu uma injeção na veia e doeu. (P.H., masculino, 12 anos, exame de sangue).

Porque a mulher me deu uma agulhada, aí doeu. (M.P., masculino, 10 anos, exame de sangue).
Rev Esc Enferm USP 2004; 38(3): 298-306. 
É mais pior mesmo que o raio x.. Só faz um bilisquinho, mas é pior. (J.L., masculino 8 anos, exame de sangue).

O exame do líquor, denominado pelas crianças como "injeção nas costas", confirmou a fama de indesejado e ruim:

Porque é bem no ossinho, e aí dói, né? (P.H., masculino, 12 anos, exame de líquor).

É o que dói mais. (A.P., feminino, 8 anos, exame de líquor).

A palavra dor foi definida de forma clara e oportuna $^{(14-15)}$, como um sofrimento físico ou moral; mágoa. Essa definição ganhou voz nos diálogos das crianças a partir do momento em que elas imprimiram relações entre a dor do corpo ou o temor de se machucar e os exames mais invasivos e causadores de tais sensações.

A tomografia computadorizada, exame de maior complexidade e aparato tecnológico, despertou a atenção das crianças que lhe foram submetidas. Por ser o tomógrafo um aparelho engenhoso e desconhecido, ele proporcionou medo. Tal sentimento, em virtude do desconhecimento do aparelho, foi agregado à dor, e a sensação dolorosa foi explicada pela necessidade de punção venosa no momento do exame, para aplicação de contrastes ou anestésicos para induzir à sedação.

Colocaram soro na minha veia, doeu viu! Eu tive medo de entrar naquela máquina, chega eu chorei. Eu fiquei com o olho fechado o tempo todo, com medo. Deus me livre! (F .A., feminino, 8 , anos, tomografia computadorizada).

Vale ressaltar que a reação ao momento vivenciado, desconhecido e aterrorizante, além de ser veemente na fala dessa última criança, fez com que ela não conseguisse se desvencilhar da dor de uma punção venosa. Exames como raio $x$, eletroencefalograma, eletrocardiograma e ultrasonografia trouxeram à tona o medo de sentir dor. Isso decorreu da temperatura fria do ambiente, fiações e ruídos estranhos nunca antes ouvidos dos aparelhos, ou talvez do fato de as crianças não terem sido informadas quanto ao que consistia o exame que realizariam e as reações que provocavam. Após terem vivenciado a experiência, puderam constatar que a dor não acompanhava tais procedimentos.
A mulher (acompanhante) que ia mais eu disse que o raio $x$ não doía, que era só uma fotinha. (E., feminino, 8 anos, raio $x$ de tórax).

Tinha uma máquina zoadenta, com uns fios que colocava no peito, nos pés e nas mãos. Eu fiquei todo amarrado e pensei que ia levar choque. Depois eu vi que era moleza. (M.P., masculino, 10 anos, eletrocardiograma).

Era só uma aguinha que colocava na barriga e fazia cócegas. Ah! Passava a barriga da gente na televisão. ( $R$, feminino, 6 anos, ultra-sonografia abdominal).

Toda criança hospitalizada tem "o direito de não sentir dor; quando existam meios para evitá-la." É o que preconiza o Estatuto da Criança e do Adolescente ${ }^{(4)}$, no artigo 18, ao afirmar que

\begin{abstract}
é dever de todos velar pela dignidade da criança e do adolescente, pondo-os a salvo de qualquer tratamento desumano, violento, aterrorizante, vexatório ou constrangedor.
\end{abstract}

Segundo a Associação Internacional de Estudo da Dor ${ }^{(16-18)}$, esta é conceituada como uma experiência sensorial e emocional desagradável associada a dano tecidual atual ou potencial ou descrita em termos do dano. Pelo exposto, a presença de dor, de acordo com a riqueza dos diálogos infantis, foi o critério utilizado para discriminar o "pior" exame.

Medo:

...Porque aí eu fico sabendo e tenho menos medo!

É direito de toda criança hospitalizada ter conhecimento adequado de sua enfermidade, dos cuidados terapêuticos e diagnósticos a serem utilizados e do prognóstico, respeitando a sua fase cognitiva, além de receber amparo psicológico quando se fizer necessário(4).

O direito à informação ampla sobre a doença e a assistência leva em consideração o respeito à criança e ao adolescente, como indivíduos capazes de entender, dentro dos limites de sua competência intelectual, o que se passa com o seu corpo e sua doença. Significa, também, que essas pessoas não poderão ser tratadas como objetos passivos da intervenção da instituição de saúde, tampouco da família, pois a opinião particular de cada criança ou adolescente deve ser con-
Percepção de crianças hospitalizadas sobre realização de exames 
Virgínia Virgilio Soares Luiza Jane E. de S. Vieira siderada. Resguarda, ainda, o direito de suporte psicológico para as suas ansiedades e fantasias.

No estudo realizado, o direito de receber uma informação compreensível sobre sua doença, exames e tratamento foi violado. $\mathrm{O}$ que se encontrou, na maioria das crianças, foi um despreparo para a realização do exame, não recebendo explicações dos mesmos e havendo apenas instruções de como agir durante a realização dos procedimentos.

Quando entrei, eu subi na cama e ele mandou eu me deitar. Aí eu perguntei se ia doer. Ele respondeu que não, porque ia fazer a anestesia. (P. H., masculino, 12 anos, tomografia).

Explicou não, só mandou eu respirar fundo e soltar o ar. (M.P., masculino, 10 anos, raio x).

Quando eu fui fazer a tomografia, ela disse que ia dar só uma picadinho na veia e que não ia doer. Depois ela disse para eu ficar quieto. (P.H., masculino, 12 anos, tomografia).

Ela só disse assim, eu não vou nem mentir, eu só vou dizer que vai doer um pouquinho. (E., feminino, 8 anos, exame de sangue).

Percebe-se a necessidade de informações sobre o exame, quando P.H. (masculino, 12 anos) indaga sobre a sensação dolorosa. As crianças em idade escolar começam a mostrar preocupação com os efeitos benéficos ou nocivos dos procedimentos. Além de quererem saber se um procedimento causará dor, elas querem saber a sua finalidade, de que modo à realização do exame as fará melhorar e em que lesão ou dor poderia resultar ${ }^{(9)}$.

Diante dessa conduta desrespeitosa explícita nas falas, a ansiedade poderá ser um dos produtos relacionados às experiências novas $\mathrm{e}$, muitas vezes, traumáticas ou assustadoras. $\mathrm{O}$ medo apareceu com freqüência na fala das crianças, seguido de nervosismo ou ansiedade. Esse sentimento surge diante de uma situação em que a pessoa se sente ou se percebe ameaçada. Pode ser entendido ${ }^{(15)}$ como um sentimento de viva inquietação ante a noção de perigo, real ou imaginário, de ameaça. Os depoimentos seguintes confirmam a importância da explicação anterior aos exames:

Eu acho importante, assim eu fico sabendo que vou fazer exame! É pra explicar. Quando eu fico com medo, eu fico logo nervoso. (N., masculino, 7 anos, exame de sangue).
Acho importante, porque aí eu fico sabendo e tenho menos medo. (E., feminino, 8 anos, exame de sangue).

Gostaria que ela me dissesse tudo, para eu não ter medo na hora. (M.P., masculino, 10 anos, exame de sangue).

Foi unânime a necessidade de uma explicação anterior à realização do exame. Tal condição deixou as crianças menos temerosas quando souberam o que as esperava, fato que pode ser comprovado por uma das que receberam explicações:

Ela mostrou o centro cirúrgico, mostrou a cama com uma pessoa toda embrulhada. Ai tinha uma televisão que passava o exame. Ela disse que um caninho ia entrar na minha boca e ia até o estômago e não doía. Se ela não tivesse explicado, eu ia ter medo porque não sabia como era o exame. (1. V., masculino, 10 anos, endoscopia digestiva).

Ficou notória a importância que uma criança conferiu à explicação e como ela foi capaz de amenizar o fator estressante do medo.

Quando J.L. (masculino, 8 anos, tomografia) diz: "É importante explicar o exame antes, porque tem pessoas que ficam com medo", ele usou um mecanismo de defesa denominado projeção, no qual projeta o medo do exame após outras crianças terem realizado e descrito suas percepções. A não - imposição do medo para si pode soar como uma demonstração de coragem, no entanto pode ser indício de um controle emocional instável, cheio de dúvidas e angústias.

As estratégias utilizadas para preparar a realização dos exames constituem-se, na sua maioria, no fornecimento de informações, estando dirigidas para os procedimentos dolorosos ou estressantes. O fornecimento de informações sensoriais se mostrou indispensável, uma vez que a criança se preocupa com essas explicações durante o exame:

Teria que dizer logo a verdade, dizer se vai doer ou não! Porque do que vai adiantar mentir, se na hora vai descobrir mesmo? (P .H., masculino, 12 anos, exame de sangue).

Além disso, o temperamento da criança, os recursos de aceitação e as experiências prévias devem ser considerados na individualização do processo preparatório.
Rev Esc Enferm USP 2004; 38(3): 298-306. 


\section{Profissional que realiza Exames:}

...Sei lá!

Quando questionadas sobre o profissional que executa o exame, encontramos respostas como: "eu acho que" ou "eu não sei". Outras arriscavam a afirmar e a apostar nas enfermeiras, enquanto algumas atribuíam essa execução aos "doutores" e "doutoras".

Não sei. (P.H., masculino, 12 anos).

Sei lá! (E., feminino, 8 anos).

Não sei, só sei que era um doutor e uma doutora.(M.P, masculino, 10 anos).

Sei, as enfermeiras.(N., masculino, 7 anos).

Acho que era uma enfermeira. (A.P., feminino, 8 anos).

São doutores! Dois homens e uma mulher. (F.A., feminino, 8 anos).

As respostas sugerem que os profissionais não se apresentavam às crianças ao realizarem os procedimentos. É possível que alguns não tenham realmente se identificado. No entanto, algum fator, como o medo ou a ansiedade, por exemplo, pode ter existido, impedindo as crianças de assimilarem essa informação; ou mesmo a comunicação entre profissional e criança pode não ter sido efetiva. Caso contrário, extraindo das respostas das crianças, podemos imaginar que essas pessoas eram meramente repetidoras de técnicas, no contexto das quais o cuidado era fragmentado em tarefas.

A associação entre a enfermeira e a realização dos exames era esperada, já que pesquisas anteriores haviam determinado essa relação, estando ainda a enfermagem intrinsecamente arraigada aos procedimentos dolorosos, como a "clássica" injeção.

Ao intitular "doutores" e "doutoras", a questão lexical se complica, tornandose mesmo semanticamente vaga. Segundo a sabedoria popular, "doutor" é aquele diplomado em uma universidade ou aquele com conhecimento superior, ou ainda diz respeito ao profissional da categoria médica. É difícil denominar a profissão de cada "doutor" em um hospital, onde a cor branca da vestimenta somada a estetoscópios, jalecos, pranchetas e frases feitas, como "Você está bem? Como passou a noite?" não esclarecem o cliente quanto à identidade profissional de quem lhe presta cuidados.
O fato de se dizer quem somos, o que fazemos e para que vimos é necessário para que a criança possa nos identificar. Porém, não será, talvez, sempre o suficiente.

\section{Atendimento esperado:}

... Atender bem, sem ignorância!

As crianças admitem o seu medo perante o exame, reconhecendo, também, a fórmula para ameniza-los: conhecer o modo como os exames são realizados e quais as sensações que esses exames causam. Uma conduta amistosa por parte dos profissionais também foi alvo de anseio:

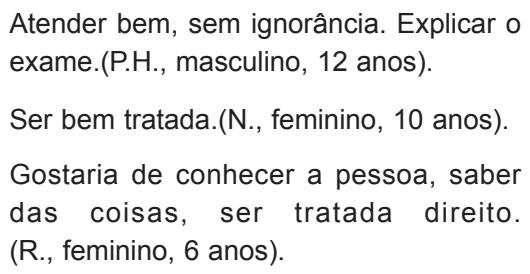

A escuta, o respeito, a amabilidade, a disponibilidade e a atenção são enfoques principais do atendimento almejado por parte das crianças -peças importantes de um quebracabeça na assistência à criança submetida a exames.

\section{CONSIDERAÇÕES FINAIS}

Identificamos que as crianças, ao mesmo tempo em que compreendem a importância do exame, exteriorizam sentimentos de medo, ansiedade, tristeza. A dor, tão temida pelas crianças, foi uma manifestação real, nada de imaginária ou mítica, desencadeada por punções venosas em sua maioria, e qualquer outro procedimento que a manifestasse. $\mathrm{O}$ medo se configurou pelo desconhecido, pelas experiências novas, pela aparelhagem, ora grande, ora pequena mas ameaçadora: por várias vezes, produtora de ruídos e ainda silencio$\mathrm{sa}$, outras vezes. A ansiedade pairava pelo também desconhecido e medo de sentir dor. Foram sensações e emoções que permearam o antes, o durante e o depois dos exames. Ficou claro que as crianças gostariam de obter informações fidedignas, verdadeiras e confiáveis sobre o modo da realização desses exames, principalmente, quando a percepção dolorosa está envolvida.

Ao retomarmos a questão da abordagem funcional, acreditamos que os profissionais vinculados diretamente ao trato das crianças
Percepção de crianças hospitalizadas sobre realização de exames 
Virgínia Virgilio Soares Luiza Jane E. de S. Vieira e responsáveis pela execução dos exames precisam interagir com elas e esclarecer suas ações, favorecendo as relações interpessoais, a escuta à criança e sua família.

Vale ressaltar que uma fundamentação sobre as características do desenvolvimen-

\section{REFERÊNCIAS}

(1) Ribeiro CA. Comportamento da criança hospitalizada: proposta de uma categorização. Acta Paul Enferm 1997; 10(1):62-73.

(2) Farias FLR. Alterações comportamentais ocasionadas pela separação mãe-filho durante a hospitalização da criança: um processo de identificação pelo enfermeiro. [dissertação] Rio de Janeiro (RJ): Escola de Enfermagem Ana Néri; 1985

(3) Soares VV, Paiva CD, Colletti, TM. Os sentimentos da criança hospitalizada de 5 a 10 anos frente à equipe de enfermagem. In: Anais do $5^{\circ}$ Encontro de Iniciação à Pesquisa; 1999 set. 16-18; Fortaleza: UNIFOR; 1999. p.284.

(4) Ministério da Ação Social. Centro Brasileiro para a Infância e Adolescência. Estatuto da Criança e do Adolescente. Brasília; 1990.

(5) Piaget J. A formação do vínculo na criança. $3^{\text {a }}$ ed. Rio de Janeiro: Zahar; 1978.

(6) Gonzaga MLC, Arruda EN. Fontes e significados de cuidar e não cuidar em hospital pediátrico. Rev Lat-Am Enferm 1998; 6(5): 17-26.

(7) Demo P. Metodologia do conhecimento científico. São Paulo: Atlas; 2000

(8) Polit DF, Hungler BP. Fundamentos de pesquisa em enfermagem. $3^{\text {a }}$ ed. Porto Alegre: Artes Médicas; 1995.

(9) Ceccim RB, Carvalho PRA. Criança hospitalizada: atenção integral como escuta a vida. Porto Alegre: UFRGS; 1997. to infantil é importante para que o profissional saiba como se comportar diante de cada situação. A qualidade da assistência é o objetivo principal dos cuidados prestados à criança e à família, visando à restauração da saúde do indivíduo numa visão global.
(10) Whaley LF, Wong DL. Enfermagem pediátrica: elementos essenciais à intervenção efetiva. $5^{\mathrm{a}}$ ed. Rio de Janeiro: Guanabara Koogan; 1999.

(11) Fundação Nacional de Saúde. Centro Nacional de Epidemiologia. Informe Epidemiológico do SUS. Brasília; 1996. Suppl 3: p.4.

(12) Minayo MCS. Desafio do conhecimento: pesquisa qualitativa em saúde. $2^{\mathrm{a}}$ ed. São Paulo: Hucitec; 1993.

(13) Lewis M, Wolkmar F. Aspectos clínicos do desenvolvimento na infância e adolescência. $3^{\mathrm{a}}$ ed. Porto Alegre: Artes Médicas; 1993.

(14) Rosa U. Dicionário compacto da língua portuguesa. $2^{a}$ ed. São Paulo: Rideel; 1993.

(15) Ferreira ABH. Minidicionário da língua portuguesa. $3^{\mathrm{a}}$ ed. Rio de Janeiro: Nova Fronteira; 1993.

(16) Einloft L, Zen J, Fuhrmester M, Dias VLM. Manual de enfermagem em UTI pediátrica. Rio de Janeiro: MEDSI; 1996.

(17) Santos LMCN, Borba RIH, Sabatés AL. A importância do preparo da criança préescolar para a injeção intramuscular com o uso do brinquedo. Acta Paul Enferm 2000; 13(2):52-8.

(18) Vila VSC, Mussi FC. O alívio da dor de pacientes no pós-operatório na perspectiva de enfermeiros de um centro de terapia intensiva. Rev Esc Enferm USP 2001; 35(3): 300-7. 